\title{
RISK ASSESSMENT OF PESTICIDE INTAKE WITH LOCAL FOOD PRODUCTS FOR ADULT HEALTH OF THE CITY OF KAZAN
}

\section{Natalya Vladimirovna Stepanova ${ }^{1}$ (D), Emiliya Ramzievna_Valeeva ${ }^{1}$ (D), Alfiya Iskhakovna Ziyatdinova ${ }^{2}$ (D), Suryana Faritovna Fomina ${ }^{1}$}

${ }^{1}$ Department of Bioecology, Hygiene and Public Health of the Institute of Fundamental Medicine and Biology, Kazan Federal University, Kazan, Russia ${ }^{2}$ Department of Human Health, Institute of Fundamental Medicine and Biology, Kazan Federal University, Kazan, Russia

Received - September 25, 2020; Revision - November 16, 2020; Accepted - December 14, 2020

Available Online December 15, 2020

DOI: http://dx.doi.org/ 10.18006/2020.8(Spl-2-AABAS).S349.S353

\section{KEYWORDS}

Organochlorine Pesticides

Dichlorodiphenyltrichloroetha ne (DDT)

Hexachlorocyclohexane $(\mathrm{HCCH})$

Foods

Health Risk

\begin{abstract}
The current study was carried out to access the effect of DDT and $\mathrm{HCH}$ contaminated local food consumption on the adult population of Kazan city. Unexpectedly, the computations considered outcomes for a wide range of food items that are covered by the dietary admission model have hazard appraisal. The degrees of non-cancer-causing hazards for the strength of the grown-up populace related with the complex entry of DDT and $\mathrm{HCCH}$ at the median (Me) level and the level of the 95th percentile with the basic food groups are identified. The ongoing dietary danger evaluation and at the degree of the 95th Percentile showed that the likelihood of Tatarstan inhabitants being presented to pesticide buildup levels that could prompt high $(\mathrm{HI}=13.41)$ negative wellbeing results. Such high levels of risk need urgent actions on the decrease of pesticide concentration and imply the development and implementation of planned curative measures.
\end{abstract}

* Corresponding author

E-mail: stepmed@mail.ru (Natalya VladimirovnaStepanova)

Peer review under responsibility of Journal of Experimental Biology and Agricultural Sciences.

Production and Hosting by Horizon Publisher India [HPI] (http://www.horizonpublisherindia.in/).

All rights reserved.
All the articles published by Journal of Experimental Biology and Agricultural Sciences are licensed under a Creative Commons Attribution-NonCommercial 4.0 International License Based on a work at www.jebas.org.

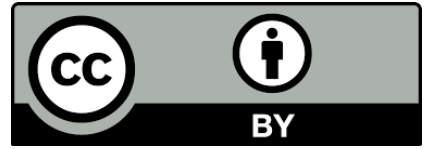




\section{Introduction}

The Republic of Tatarstan (RT) makes the top three among the regions of RF in the amount of agricultural output. According to the data of the Food and Agricultural Organization of the United Nations (FAO), annual potential crop losses from noxious organisms (pests) reach 30\%, and the use of pesticides is considered to be the most effective method of pest control. The yield misfortunes from a complex of irritation, plant illnesses and weeds can make $25-30 \%$ without completing appropriate unique exercises (Goncharov, 2010). According to expert assessments, the profitability of activities on crop protection in Russia ranges from $120 \%$ (on grain) to $516 \%$ (on the potato) (Istomin et al., 2014). Organochlorine pesticides (OCP) - global contaminants: hexachlorocyclohexane ( $\alpha, \beta, \gamma-$ isomers), DDT and its metabolites are controlled in all types of food stock and foods. The critical factor in OCP assessment and hazard prediction is their environmental persistence (stability), ability to overcome long food chains, persistence in environmental compartments for many years (cumulative properties) and also have many remote effects (Zybalov \& Krupnova, 2014). Low solubility in water and high solubility in fats is precisely responsible for the retention of DDT in fat cells. DDT accumulates in animal fats; hence meat, fish, poultry, eggs, cheese, butter and milk belong to foods, which often contain the highest levels of DDT. A high retention rate of DDT indicates that toxic effects can be manifested for a long period, as well as at a considerable geographic distance from the place of exposure (Tsakiris et al., 2015; Raslan et al., 2018).

The relevance of research is caused by the agricultural specialization of the Republic of Tatarstan. Therewith, the level of meeting the nutritional requirements utilizing local production foods grows, as a rule, among the population (Fomina \& Stepanova, 2017). The main route of the pesticides' entry into the body (apart from professional groups of the population) is the gastrointestinal tract, which is most vulnerable to ecotoxicants' exposure (Khamitova et al., 2020). The World Health Organization (WHO) considers monitoring of hygienic food safety to be an essential subsystem for the population health risk assessment, because, depending on conditions, from 30 to $80 \%$ of potentially harmful chemicals enter the human body with foods (Fomina \& Stepanova, 2018). The current study aimed to evaluate the section of DDT and $\mathrm{HCCH}$ with diet and the degree of non-cancer-causing hazard for the strength of the grown-up populace of the city of Kazan dependent on the information of social-clean checking of the controlled pesticides.

\section{Materials and Methods}

Nowadays, pesticides containing lead, mercury, arsenic, polychlorinated biphenyls are in the basic list of chemical contaminants in RF. Analysis of food contamination and exposure assessment was based on the results of retrospective studies of DDT and HCCH residual concentrations in foods performed by the laboratory of the Federal State-Funded Healthcare Institution "The Center of Hygiene and Epidemiology in the Republic of Tatarstan" for the years of 2010-2018 using thin-layer chromatography (DDT and its metabolites, $\mathrm{HCCH}$ ). The calculation of average daily doses of toxic elements' entry into the body of the child and adult populations with basic food groups was carried out with the account of edible food parts and following sections 3.6 of Guidelines 1.2.3216-14"Risk assessment of the impact of pesticide residual quantities in foods on the population"(Guidelines 1.2.3216-14, 2010). The median and the 95th percentiles of the content of pesticide residual quantities in foods were applied for exposure calculation.

Evaluation of the danger of creating non-cancer-causing impacts from pollutants entering the body with nourishments was acted as per Guidelines for hazard appraisal for the populace wellbeing on presentation to synthetics debasing the climate(P 2.1.10.192004)(P 2.1.10.1920-04, 2004). The values of acceptable daily doses (ADD) of pesticide active ingredients were obtained from databases (HN 1.2.2701-18, EU, EPA, WHO, Codex Alimentarius).

\section{Results and Discussion}

Assessment of the levels of residual pesticides quantities in agriculture product was carried out following hygienic normative for pesticides' content in environmental compartments GN 1.2.3539-18 "Hygienic normative for pesticides' content in environmental compartments". Results of DDT and HCCH monitoring in basic food groups for the years of 2011-2018 are given in Tables 1 .

Comparison of DDT concentrations at the Me and $95^{\text {th }}$ Percentile levels with MAL revealed the higher MAL for certain food groups (Table 1). At the level of the $95^{\text {th }}$ Percentile, exceedance by a factor of 10.5 was registered for milk and dairy products, by a factor of 1.7 for cereals and bakery goods, and by a factor of 2 for fruits and vegetables. At the Me level, MAC exceeded the recommended values by a factor of 1.5 for milk and dairy products, and by a factor of 3 for fruits and vegetables.

At the level of $95^{\text {th }}$ Percentile, the maximum allowable level (MAL) exceeded by a factor of 2.7 for meat and meat products, by a factor of 4.5 for milk and dairy products, by a factor of 3 for fish and fish products, by a factor of 5 for cereals and bakery goods, and by a factor of 2.7 for fruits and vegetables.

To calculate exposure, the data on the content of the examined pesticides in foods and on the amount of foods taken by the adult population of the city of Kazan. Assessment of the adult 
population nutrition was performed according to the data from Territorial body of Federal state statistics service for the Republic of Tatarstan by sampling survey of the diet and was based on the inquiry of the residents with the account of regional exposure factors (bodyweight) determined by results of the questionnairebased survey. Results of long-term (chronic) exposure assessment in basic food groups for every pesticide (scenarios with upper and medium limits) are given in Tables 2, 3 .

The value of total daily exposure at the Me level (0.0059), and the degree of the 95th percentile appeared (0.0176), and did not exceed the recommended value of acceptable daily dose (ADD) for DDT in $0.01 \mathrm{mg} / \mathrm{kg}$ of the bodyweight of an adult person.

The positioning of nourishments concerning commitment to the allout introduction demonstrated that the significant commitment to DDT presentation was made by milk and dairy items $(47.8 \%$ at the Me level, and $41.8 \%$ at the degree of the 95-th percentile), grains and bread kitchen merchandise (34\% at the Me level and $32 \%$ at the degree of the 95-th percentile), meat and meat items $(8.4 \%$ at the Me level and $10.3 \%$ at the degree of the 95-th percentile), and foods are grown from the ground $(7 \%$ at the Me level and $12.3 \%$ at the degree of the 95-th percentile). Risk record (HI) at the Me level made 1.68 , which compared to an adequate level (HI=1.1-3.0). Peril record (HI) of DDT passage at the degree of the 95-th percentile made 5.03, which compared to disturbing level (HI from 3 to 6) (Table 4).
Table 1 The content of DDT and HCH in separate groups of products (at the level of Me and $95 \mathrm{R}$ ) as per the monitored data

\begin{tabular}{|c|c|c|c|c|c|c|}
\hline \multirow{2}{*}{ Product group } & \multicolumn{3}{|c|}{ DDT } & \multicolumn{3}{|c|}{$\mathrm{HCH}$} \\
\hline & $\begin{array}{c}\mathrm{MDU} \\
(\mathrm{mg} / \mathrm{kg})\end{array}$ & $\mathrm{Me}$ & $95 \mathrm{P}$ & $\begin{array}{c}\mathrm{MDU} \\
(\mathrm{mg} / \mathrm{kg})\end{array}$ & $\mathrm{Me}$ & $95 \mathrm{P}$ \\
\hline $\begin{array}{c}\text { Meat and meat } \\
\text { products; bird eggs }\end{array}$ & 1.0 & 0.134 & 0.241 & 0.1 & 0.059 & 0.265 \\
\hline $\begin{array}{l}\text { Milk and Dairy } \\
\text { Products }\end{array}$ & 0.02 & 0.0358 & 0.211 & 0.05 & 0.072 & 0.229 \\
\hline $\begin{array}{c}\text { Fish, non-fish fishing } \\
\text { objects }\end{array}$ & 0.3 & 0.0222 & 0.121 & 0.03 & 0.026 & 0.089 \\
\hline $\begin{array}{l}\text { Grain, cereals and } \\
\text { bakery products }\end{array}$ & 0.1 & 0.0143 & 0.170 & 0.1 & 0.154 & 0.530 \\
\hline $\begin{array}{l}\text { Sugar and } \\
\text { confectionery }\end{array}$ & 0.02 & 0.0075 & 0.023 & 0.2 & 0.018 & 0.063 \\
\hline Fruits and vegetables & 0.1 & 0.3466 & 0.2057 & 0.1 & 0.043 & 0.273 \\
\hline $\begin{array}{l}\text { Oilseeds and fatty } \\
\text { foods }\end{array}$ & 0.1 & 0.0096 & 0.0353 & 0.2 & 0.022 & 0.155 \\
\hline
\end{tabular}

MRL - the maximum permissible level;

Table 2 Assessment results of $\mathrm{HCH}$ exposure to dietary intake by major food groups

\begin{tabular}{|llllc|}
\hline Product group & $\mathrm{Me}$ & $95 \mathrm{P}$ & $\mathrm{kg} /$ day & $\mathrm{kg} /$ week \\
\hline Meat and meat products; bird eggs & 0.059 & 0.265 & 0.215 & 1.502 \\
\hline Milk and Dairy Products & 0.072 & 0.229 & 1.001 & 7.01 \\
\hline Fish, non-fish fishing objects & 0.026 & 0.089 & 0.027 & 0.19 \\
\hline Grain, cereals and bakery products & 0.154 & 0.530 & 0.335 & 2.348 \\
\hline Sugar and confectionery & 0.016 & 0.063 & 0.114 & 0.801 \\
\hline Fruits and vegetables & 0.043 & 0.273 & 0.247 & 1.730 \\
\hline Oilseeds and fatty foods & 0.022 & 0.155 & 0.046 & 0.323 \\
\hline
\end{tabular}

MRL - the maximum permissible level

Table 3 Results of assessing the exposure to DDT coming from the diet for the main product groups

\begin{tabular}{|lcccc|}
\hline Product group & $\mathrm{Me}$ & $95 \mathrm{P}$ & $\mathrm{kg} /$ day & $\mathrm{kg} /$ week \\
\hline Meat and meat products; bird eggs & 0.134 & 0.241 & 0.215 & 1.502 \\
\hline Milk and Dairy Products & 0.036 & 0.211 & 1.001 & 7.01 \\
\hline Fish, non-fish fishing objects & 0.022 & 0.121 & 0.027 & 0.188 \\
\hline Grain, cereals and bakery products & 0.014 & 0.170 & 0.335 & 2.348 \\
\hline Sugar and confectionery & 0.008 & 0.023 & 0.114 & 0.801 \\
\hline Fruits and vegetables & 0.346 & 0.206 & 0.247 & 1.730 \\
\hline Oilseeds and fatty foods & 0.01 & 0.035 & 0.046 & 0.323 \\
\hline
\end{tabular}


Table 4 The total risk level of DDT and HCH with the diet of the grown-up populace of the city of Kazan

\begin{tabular}{|c|c|c|c|c|c|c|c|c|}
\hline \multirow[t]{2}{*}{ Product Groups } & \multicolumn{2}{|c|}{ DDT } & \multicolumn{2}{|c|}{$\mathrm{HCH}$} & \multicolumn{4}{|c|}{$\mathrm{DDT}+\mathrm{HCH}$} \\
\hline & HQ Me & HQ 95 perc & HQ Me & HQ 95 perc & $\mathrm{HI} \mathrm{Me}$ & $\%$ & HI $95 \mathrm{P}$ & $\%$ \\
\hline Meat and meat products; bird eggs & 0.308 & 0.688 & 0.236 & 0.869 & 0.545 & 12.119 & 1.557 & 11.606 \\
\hline Milk and Dairy Products & 0.385 & 2.807 & 1.343 & 3.505 & 1.728 & 38.449 & 6.311 & 47.065 \\
\hline Fish, non-fish fishing objects & 0.006 & 0.043 & 0.013 & 0.037 & 0.019 & 0.428 & 0.08 & 0.594 \\
\hline Grain, cereals and bakery products & 0.051 & 0.759 & 0.962 & 2.719 & 1.013 & 22.542 & 3.478 & 25.938 \\
\hline Sugar and confectionery & 0.009 & 0.035 & 0.038 & 0.111 & 0.047 & 1.040 & 0.146 & 1.091 \\
\hline Fruits and vegetables & 0.920 & 0.675 & 0.199 & 1.031 & 1.119 & 24.903 & 1.707 & 12.727 \\
\hline Vegetable oil and other fats & 0.005 & 0.022 & 0.019 & 0.109 & 0.023 & 0.519 & 0.131 & 0.976 \\
\hline Total Risk (HI) & 1.686 & 5.029 & 2.81 & 8.381 & 4.495 & 1.00 & 13.41 & 1.00 \\
\hline
\end{tabular}

The non-carcinogenic risk of $\mathrm{HCCH}$ at the Me level for milk and dairy products was assessed as alarming (hazard quotient (HQ = 1.1-3.0) based on the research findings. The value of noncarcinogenic risk at the level of the 95th percentile for milk and dairy products corresponded to the high-risk level (HQ $=3$ and more). An alarming risk (HQ $=1.1-3$ ) was identified for cereals, bakery goods, fruits, and vegetables. Total hazard index (HI) at the Me level made 2.81, which corresponded to the allowable range (HI=1.1-3.0) of non-carcinogenic risk. The hazard index (HI) at the level of the 95th Percentile identified a high-risk level $(\mathrm{HI}=8.38)$ of non-carcinogenic effects.

Therefore long-term intake of foods containing residues of organochlorine pesticides exceeding maximum allowable levels (MAL) is a potential hazard for the population health in the Republic of Tatarstan. Organochlorine compounds partially excrete from the body; therefore they can be detected in fats and lipids in the form of a primary molecule and metabolites for a long time. Some preparations of this group can cause long-term effects (Karr et al., 2006; Courland, 2011; Rakhmanin et al., 2015). Assessment of long-term entry with the diet of an individual consumer predicts a life-long exposure to pesticides' residues in a diet. The inclusion of $\mathrm{HCCH}$ with diet in a grown-up populace of RT makes the significant commitment in add up to non-cancercausing hazard (HI) on the complex passage of DDT with $\mathrm{HCCH}$ at the Me and the 95-th percentile levels $(62.5 \%)$. The results of assessing complex entry of DDT and $\mathrm{HCCH}$ with the diet of the adult population of the Republic showed that the total risk level at the Me level corresponded to an alarming level $(\mathrm{HI}=4.495)$. This risk level is acceptable only for professional groups of the population and implies the development and implementation of planned curative measures.

The complex entry of DDT and HCCH at the level of the 95-th percentile refers to the indices of the high level of the noncarcinogenic health impact and risk level $(\mathrm{HI}=13.41)$. Such levels are unacceptable for all groups of the adult population and their reaching requires carrying out urgent actions on their decrease (Galani et al., 2020). Current studies show that OCP, OPP, and copper-containing preparations contribute to the growth of type 1 or type 2 diabetes mellitus incidence in 2-10 years (Khamitova, 2015). Obesity, high blood sugar level, and the presence of type 2 diabetes are associated with higher concentrations of DDT and its metabolites, although a statistically significant relationship was not identified (Tsakiris et al., 2011; Stepanova, 2018).

\section{Conclusions}

Based on the analysis of the pesticides' monitoring results for the period of 2011-2018 the necessity of developing recommendations for the improvement of Russian monitoring system effectiveness for the provision of a high level of consumer protection. So far, governmental orders are required to include more number of pesticides into monitoring programs. More than 1000 pesticides were used over the last century, and at present many new pesticides are developed and are being developed, and this fact specifies the urgent need for carrying out both targeted and nontargeted screening of these compounds in foods to include them in the basic list of food safety control. Apart from the absence of well-grounded priorities of the health risk for the population on certain territories, insufficiently effective coordination between participants working in this field (farmers, medical workers, executive authorities) impedes the effectiveness of measures on negative consequences prevention. The problem exists, but to a different extent, and in all countries. Results of the food monitoring programs are an important source of information for the assessment of the pesticide residues' impact on the consumer at the regional level. At present, the population health risk assessment from exposure to environmental hazards is a research area of vital importance. Therewith, assurance of territorial (neighborhood) levels with the record of a complex of ecologo-sterile elements on the domain under investigation, for example, populace dismalness, 
the ecological status, and wellbeing hazard evaluation from presentation to hurtful natural components stay a key angle. The accessible information shows that introduction to pesticides and pollutants substances, which enter into the body with nourishments, stays a significant issue for general wellbeing.

\section{Acknowledgments}

This work was supported by the endowment apportioned to Kazan Federal University for the state task in the circle of logical exercises

\section{Conflict of Interest}

Authors would hereby like to declare that there is no conflict of interests that could possibly arise.

\section{References}

Courland BA (2011) Preventive toxicology: problems, tasks, prospects. Toxicological Bulletin 6: 20-22.

European Food Safety Authority (2018) The 2016 European Union report on pesticide residues in food. EFSA Journal 16(7): 5348, 139. https://doi.org/10.2903/j.efsa.2018.5348.

Fomina S, Stepanova N (2018) Peculiarities in nutrition of the adult population of the city of Kazan. European journal of clinica investigation 48: 163 .

Fomina SF, Stepanova NV (2017) Non-carcinogenic risk to the health of the children of Kazan due to contamination of food products and raw materials. Health Risk Analysis 4: 42-48.

Galani Y Joseph Hubert, Houbraken M, Wumbei A, Djeugap Joseph F, Fotio D,' YunGong Y, Spanoghe P (2020) Monitoring and dietary risk assessment of 81 pesticide residues in 11 local agricultural products from the 3 largest cities of Cameroon. Food Control 118. Available online 20 June 2020, 107416 https://doi.org/10.1016/j.foodcont.2020.107416.

Goncharov IR (2010) Development of innovative processes in plant protection. Protection and quarantine of plants 4: P.4-7.

Guidelines 1.2.3216-14(2010) Risk assessment of the impact of pesticide residual quantities in foods on the population. - M.: Federal Center for Hygiene and Epidemiology of Russia: 27 p.

Istomin AV, EliseevYuYu, EliseevYuV (2014) Conditionality of risks to children's health by chemical contamination of food products in the region. Public health and habitat 2(251): 19-21.

Karr C, Murphy H, Glew G et al. (2006) Pacific Northwest health professionals survey on pesticides and children 11(3-4): $113-120$.

Khamitova RJ, Valeeva ER, Stepanova NV, Ziatdinov VB, Sabirzyanov AR, Elagina DS (2020) Statistical investigation on effect of resource-saving technologies on diabetes mellitus incidence (A case study of the republic of Tatarstan). International Journal of Pharmaceutical Researchю 12(1): 836 - 842.

Khamitova RYa (2015) Chemical factor in the development of endocrinological diseases. Hygiene and Sanitation 8(94): 12-16.

P 2.1.10.1920-04 (2004) Guidelines for assessing public health risk from exposure to chemicals that pollute the environment. - M.: Federal Center for Sanitary Inspection of the Ministry of Health of Russia: Pp. 143.

Rakhmanin YuA, Novikov SM, Avaliani SL, Sinitsyna OO, Shashina TA (2015) Modern problems of assessing the risk of environmental factors on public health and ways to improve it. Health Risk Analysis 2: 4-11.

Raslan AA, Elbadry S, Sobhy WD (2018) Estimation and Human Health Risk Assessment of Organochlorine Pesticides in Raw Milk Marketed in Zagazig City, Egypt. Journal of Toxicology. - .pp. 1-8 https://doi.org/10.1155/2018/3821797.

Stepanova N (2018) Contribution of endocrine disruptor pesticides exposures to non-contagious diseases of adult population. European Journal of Clinical Investigation 48(S1): P. 105.

Tsakiris IN, Goumenou M, Tzatzarakis MN, Alegakis AK, Tsitsimpikou K, Ozcagli E, Vynias D, Tsatsakis AM (2015) Risk assessment for children exposed to DDT residues in various milk types from the Greek market. Food and Chemical Toxicology 75: $156-165$.

Tsakiris IN, Toutoudaki M, Kokkinakis M, Paraskevi M, Tsatsakis AM (2011) A risk assessment study of greek population dietary chronic exposure to pesticide residues in fruits, vegetables and olive oil. In: Stoytcheva M (Ed.) Pesticides-formulations, effects, fate. InTech: 253-268.

Zybalov VS, Krupnova TG (2014) Study of the content of organochlorine pesticides in environmental objects in the Chelyabinsk region. Bulletin of the South Ural State University. Series "Chemistry" 6(3): 39-43. 